\title{
SISTEM PEMASARAN JERUK SIAM GUNUANG OMEH DENGAN PENDEKATAN STRUCTURE, CONDUCT, PERFORMANCE (SCP) DI KABUPATEN LIMA PULUH KOTA
}

\author{
MARKETING SYSTEM OF GUNUANG OMEH SIAM ORANGE \\ WITH STRUCTURE, CONDUCT, PERFORMANCE (SCP) APPROACH \\ IN LIMA PULUH KOTA DISTRICT
}

\author{
Rahma Dini, Mega Amelia Putri ${ }^{*}$, John Nefri \\ Program Studi Pengelolaan Agribisnis, Politeknik Pertanian Negeri Payakumbuh, \\ Jln. Raya Negara KM 07 Tanjung Pati Kec. Harau, Kab. Lima Puluh Kota, \\ Sumatera Barat, Indonesia \\ *E-mail: lia.politani@gmail.com
}

(Diterima 27-12-2021; Disetujui 22-01-2022)

\begin{abstract}
ABSTRAK
Sistem pemasaran jeruk siam gunuang omeh (JESIGO) memiliki permasalahan yang kompleks, baik dari sisi harga maupun non harga. Kondisi harga jeruk yang relatif tinggi $(69.23 \%)$ dibandingkan dengan jeruk jenis lainnya berakibat kondisi pasar jeruk menjadi tidak kompetifif. Di sisi lain, petani sebagai produsen tidak mampu menentukan harga jualnya, peran lembaga

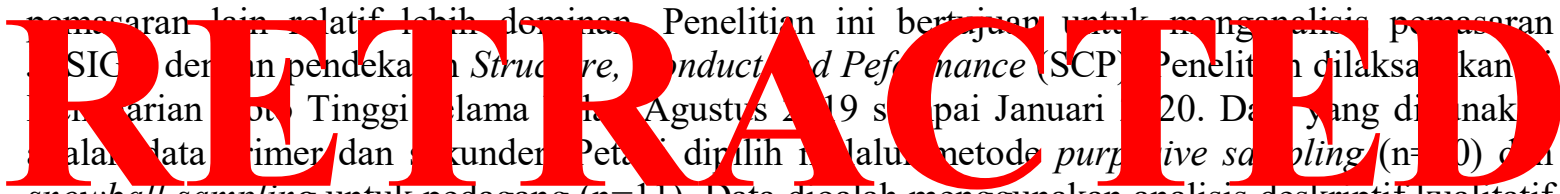

snowball sampling untuk pedagang $(\mathrm{n}=11)$. Data dioalah menggunakan analisis deskrıptif kualitatif dan kuantitatif. Berdasarkan hasil analisis struktur pasar, pemasaran JESIGO cendrung mengarah kepada struktur pasar oligopsoni. Dilihat dari perilaku pasar, terdapat 4 saluran pemasaran dan fungsi pemasaran yang dilakukan lembaga-lembaga pemasaran, yaitu fungsi pertukaran, fungsi fisik dan fungsi fasilitas. Sedangkan analisis kinerja pasar menunjukkan bahwa, share harga yang diterima petani (farmer's share) sudah tergolong tinggi $(>40 \%)$. Margin pemasaran terbesar dinikmati oleh pedagang pengecer pada saluran 3. Hasil analisis struktur, perilaku dan kinerja pasar JESIGO menggambarkan bahwa pasar mengarah pada kondisi efisien.
\end{abstract}

Kata kunci: efisiensi pemasaran, farmer's share, margin, oligopsoni

\section{ABSTRACT}

The Gunuang Ameh Siam orange (JESIGO) marketing system has complex problems, both in terms of price and non-price. The condition of the relatively high price of oranges $(69.23 \%)$ compared to other types of oranges has resulted in uncompetitive orange market conditions. On the other hand, farmers as producers are not able to determine the selling price, the role of other marketing institutions is relatively more dominant. This study aims to analyze the marketing of JESIGO with a Structure, Conduct and Performance (SCP) approach. The research was carried out in Kenagarian Koto Tinggi during August 2019 to January 2020. The data used were primary and secondary data. Farmers were selected through purposive sampling $(n=20)$ and snowball sampling for traders $(n=11)$. The data were processed using qualitative and quantitative descriptive analysis. Based on the analysis of market structure, JESIGO marketing tends to lead to an oligopsony market structure. Judging from market behavior, there are 4 marketing channels and marketing functions performed by marketing institutions, namely the exchange function, physical function and facility function. Meanwhile, market performance analysis shows that the share of prices received by farmers (farmer's share) is quite high (>40\%). The largest marketing margin is enjoyed by 


\section{SISTEM PEMASARAN JERUK SIAM GUNUANG OMEH DENGAN PENDEKATAN STRUCTURE, \\ CONDUCT, PERFORMANCE (SCP) DI KABUPATEN LIMA PULUH KOTA \\ Rahma Dini, Mega Amelia Putri, John Nefri}

retailers in channel 3. The results of the analysis of the structure, behavior and market performance of the JESIGO orange illustrate that the market is in an efficient condition.

Keywords: marketing efficiency, farmer's share, margin, olygopsony

\section{PENDAHULUAN}

Jeruk Siam merupakan salah satu jenis buah-buahan yang paling banyak dikembangkan dan yang paling luas penyebarannya di Indonesia. Menurut (Badan Pusat Statistik, 2018a) bahwa total produksi jeruk siam di Indonesia menduduki peringkat ketiga setelah pisang dan mangga, dengan total produksi sebanyak 2.4 juta ton. Kabupaten Lima Puluh Kota menjadi sentra produksi jeruk siam di Sumatera Barat. Varietas jeruk yang dikembangkan adalah Jeruk Siam Gunuang Omeh (JESIGO). Dinamakan JESIGO karena jeruk ini dibudidayakan di Kecamatan Gunuang Omeh. Kecamatan Gunuang Omeh merupakan daerah dengan kontribusi jeruk siam paling besar di Kabupaten Lima Puluh Kota jika dibandingkan dengan kecamatan lainnya yaitu sebesar 95.37\% dari keseluruhan total produksi pada tahun $2015(7,848.1$ ton) (Badan Pusat Statistik, 2018b).

Kenagarian Koto Tinggi merupakan daerah dengan persentase jumlah petani terbanyak yaitu sebesar $70.5 \%$ (987 petani). Total luas lahan yang ditanami jeruk sebanyak 42.75 persen
(388.64 ha). Hal ini menunjukkan bahwa struktur ekonomi di Kenagarian Koto Tinggi sebagian besar bertumpu pada sektor perkebunan jeruk. Besarnya tingkat produksi jeruk siam di Kecamatan Gunuang Omeh juga harus diimbangi dengan pemasaran yang baik. Menurut (Gisti et al., 2018) salah satu permasalahan yang dihadapi komoditas ini adalah fluktuasi harga.

Saat ini harga jual jeruk siam relatif lebih mahal 69,23\% dari produk pesaing. Tingginya harga jual akan berdampak terhadap lembaga pemasaran yang terlibat. (Nilayani et al., 2021) menyatakan bahwa faktor penghambat bagi petani antara lain adanya penurunan harga jeruk secara drastis akibat terjadinya panen raya. Selain itu, kondisi harga jeruk yang tidak menentu menjadi risiko tersendiri bagi petani tertutama akibat tidak seimbangnya pengeluaran untuk pembelian faktor-faktor produksi seperti pupuk dan biaya perawatan. Oleh karena itu, pemasaran jeruk siam memerlukan suatu pendekatan khusus untuk mampu mengantisipasi ketidakstabilan harga dan keterlibatan setiap lembaga pemasaran dalam 
mempengaruhi suatu harga yang terbentuk.

Pendekatan Structure, Conduct, Peformance (SCP) dapat menjawab permasalahan pemasaran yang bersifat kompleks. Hubungan paling sederhana dari ketiga variabel tersebut adalah hubungan linier dimana struktur mempengaruhi perilaku dan kemudian mempengaruhi kinerja (Putri et al., 2015; Panagiotou, 2006). SCP digunakan untuk menganalisa pemasaran dengan melihat struktur pasar, perilaku pasar dan keragaan pasar pada masing-masing lembaga pemasaran. Tujuan dari penelitian ini adalah untuk menganalisis struktur pasar, perilaku pasar dan kinerja pasar pada pemasaran jeruk siam Gunuang Omeh.

\section{METODE PENELITIAN}

Penelitian dilakukan di Kenagarian Koto Tinggi, Kecamatan Gunuang Omeh, Kabupaten Lima Puluh Kota, Propinsi Sumatera Barat. Pemilihan lokasi dilakukan dengan sengaja mengingat daerah ini merupakan sentra pengembangan jeruk siam. Sampel ditentukan secara purposive terhadap lokasi dan responden. Jumlah petani responden yang diambil sebanyak 20 orang, dimana petani yang dijadikan sebagai responden adalah petani yang memiliki jumlah pohon jeruk produktif paling sedikit 250 batang. Sedangkan sampel lembaga pemasaran dilakukan dengan menggunakan teknik snowball sampling berdasarkan alur pemasaran yang ada di Kenagarian Koto Tinggi. Jumlah lembaga pemasaran terdiri atas 8 orang pedagang pengepul, 8 orang pedagang pengecer dalam daerah, dan 3 orang pengecer luar daerah. Data penelitian menggunakan data primer dan sekunder. Data primer dari pelaku pemasaran meliputi jumlah produksi/ pembelian, harga pembelian dan penjualan, serta pengeluaran yang terjadi. Data sekunder berasal dari instasi terkait seperti Dinas Pertanian,, Koperasi, Kelompok Tani dan BPS. Secara sederhana merode analisis ditampilkan pada Tabel 1.

Tabel 1. Metode Analisis Pendekatan SCP

\begin{tabular}{lll}
\hline Pendekatan & \multicolumn{1}{c}{ Analisis } & \multicolumn{1}{c}{ Keterangan } \\
\hline Struktur & Pangsa Pasar (Market & Ratio antara pembelian jeruk siam di tingkat pengepul terhadap \\
Pasar & Share $)$ & $\begin{array}{l}\text { total transaksi pembelian di Kenagarian Koto Tinggi satuan } \\
\text { persentase }(\%)\end{array}$ \\
& Konsentrasi Pasar & $\begin{array}{l}\text { Diidentifikasi dari total jumlah pembelian dari empat pembeli } \\
\text { terbanyak (CR4) dalam satuan Kg/Minggu }\end{array}$ \\
& $\bullet$ CR4 $\leq 33 \%$ (competitive marjet structure)
\end{tabular}


Hambatan Masuk Pasar

$\begin{array}{ll}\text { Perilaku } & \begin{array}{l}\text { Menekankan pada } \\ \text { analisis deskriptif dari } \\ \text { Pasar }\end{array} \\ \begin{array}{l}\text { fenomena yang } \\ \text { ditemukan di lapangan }\end{array} \\ \text { Kinerja } & \text { Margin Pemasaran } \\ \text { Pasar } & \end{array}$

Farmer's share
- CR4 berkisar antara 33\%-50\% (weak oligopsonist market structure)

- CR4>50\% (strongly oligopsonist market structure)

Dianalisis dengan menggunakan Minimum Efficiency Scale (MES). Diperoleh dengan membandingkan nilai rata-rata output empat perusahaan terbesar dengan output total keseluruhan transaksi pembelian

Sistem pembentukan harga, praktek pembelian dan penjualan, kerjasama lembaga pemasaran dan sistem pembayaran

Perbedaan harga yang dibayarkan konsumen dengan harga yang diterima oleh produsen $(\mathrm{Rp} / \mathrm{Kg})$

Rasio antara harga di tingkat petani terhadap harga di tingkat retail

Nilai $\leq 40 \%$ Kategori Rendah Nilai $>40 \%$ Kategori Tinggi

\section{HASIL DAN PEMBAHASAN}

\section{Struktur Pasar (market structure)}

Analisis struktur pasar bertujuan untuk mengidentifikasi tingkat persaingan yang terjadi dalam pemasaran JESIGO di Kenagarian Koto Tinggi. Identifikasi dilakukan dengan melakukan analisis terhadap pangsa pasar, konsentrasi pasar, dan hambatan masuk pasar. Melalui analisis ini dapat diketahui bentuk pasar yang terjadi dalam pemasaran JESIGO.

\section{a. Pangsa Pasar}

Pangsa pasar (market share) adalah persentase pasar yang ditentukan dalam ukuran unit maupun revenue dan dihitung berdasarkan spesific entity, Pangsa pasar (market share) adalah persentase pasar yang ditentukan dalam ukuran unit maupun revenue dan dihitung berdasarkan spesific entity, disebut juga sebagai indikator tentang apa yang dilakukan oleh sebuah perusahaan terhadap kompetitornya (Panagiotou, 2006). Pangsa pasar 8 pedangang pengepul dapat dilihat pada Tabel 2.

Tabel 2. Pangsa Pasar 8 Lembaga Pemasaran (Pedangang Pengepul) Jesigo di Kenagarian Koto Tinggi

\begin{tabular}{cccc}
\hline No & Nama & $\begin{array}{c}\text { Rata-rata } \\
\text { Volume } \\
\text { Pembelian } \\
\text { JESIGO } \\
\text { (Kg/Minggu) }\end{array}$ & $\begin{array}{c}\text { Pangsa } \\
\text { Pasar } \\
\text { (\%) }\end{array}$ \\
\hline 1 & Pengepul 1 & 13.000 & 15,02 \\
2 & Pengepul 2 & 14.000 & 16,18 \\
3 & Pengepul 3 & 13.000 & 15,02 \\
4 & Pengepul 4 & 12.000 & 13,87 \\
5 & Pengepul 5 & 7.500 & 8,67 \\
6 & Pengepul 6 & 9.000 & 10,40 \\
7 & Pengepul 7 & 10.000 & 11,56 \\
8 & Pengepul 8 & 8.000 & 9,24 \\
\hline & Jumlah & $\mathbf{8 6 . 5 0 0}$ & $\mathbf{1 0 0}$ \\
\hline
\end{tabular}

Sumber: Data diolah (2020)

Berdasarkan Tabel 2, lembaga pemasaran (perusahaan) yang memiliki pangsa pasar terbesar adalah Pengepul 2 (16.18\%), selanjutnya diikuti oleh Pengepul 1 dan $3(15.02 \%)$ serta Pengepul $4 \quad(13.87 \%)$. Keempat 
perusahaan ini merupakan lembaga pemasaran ditingkat pedagang pengepul.

\section{b. Konsentrasi Pasar}

Berdasarkan pangsa pasar, konsentrasi pasar dapat diketahui dengan menghitung $\mathrm{CR}_{4}$ (Concentration Ratio for The Bigest Four). Menurut (Cramer, 2009), $\mathrm{CR}_{4}$ merupakan penjumlahan pangsa pasar empat perusahaan terbesar dari suatu wilayah pasar. Perhitungan $\mathrm{CR}_{4}$ nantinya akan menggambarkan struktur pasar dari sudut pembeli. Pendekatan $\mathrm{CR}_{4}$ digunakan untuk melihat persentase total input empat pedagang pengepul terbesar terhadap total input seluruh pedagang pengepul yang membeli JESIGO.

$$
\begin{gathered}
\text { CR4 }=16,18 \%+15,02 \%+15,02 \% \\
+13,87 \% \\
=60,11 \%
\end{gathered}
$$

Berdasarkan hasil perhitungan nilai $\mathrm{CR}_{4}$ menunjukkan bahwa empat perusahaan terbesar menguasai $60,11 \%$ dari total ketersediaan JESIGO di Kenagarian Koto Tinggi. Artinya tingkat persaingan pedagang pengepul JESIGO di Kenagarian Koto Tinggi terkonsentrasi dengan tingkat persaingan yang kecil. Hal ini menunjukkan bahwa Jeruk Siam Gunuang Omeh memiliki struktur pasar oligopsoni. Ini sesuai dengan pendapat (Kohls \& Uhl, 2002) yang menyatakan apabila rasio konsentrasi empat perusahaan terbesar lebih besar dari 50 $\%$, maka struktur pasar cendrung berada pada kondisi ologopsoni. Pasar oligopsoni merupakan suatu kondisi pasar dimana terdapat sedikit pembeli sementara produsen yang menawarkan produknya banyak.

c. Hambatan Masuk Pasar

$$
\text { Segala sesuatu yang }
$$

memungkinkan terjadinya penurunan kesempatan atau kecepatan masuknya pesaing baru merupakan hambatan untuk masuk pasar. Hambatan masuk pasar dapat dihitung menggunakan Minimun Efficiency Scale (MES). Nilai MES diperoleh dari nilai rata-rata pembelian JESIGO 4 perusahaan terbesar di Kenagarian Koto Tinggi terhadap total pembelian jesigo oleh seluruh perusahaan di Kenagarian Koto Tinggi. Menurut (Putri et al., 2013) jika nilai MES lebih besar dari 10 persen mengindikasikan bahwa terdapat hambatan masuk dalam pasar JESIGO di Kenagarian Koto Tinggi.

$$
\begin{aligned}
& M E S \\
& =\frac{\text { Rata }- \text { rata pembelian 4 perusahaan terbesar }}{\text { total pembelian seluruh perusahaan }} \\
& \begin{aligned}
M E S=\frac{5.375}{32.000} \\
=0.15
\end{aligned}
\end{aligned}
$$


Berdasarkan perhitungan didapatkan nilai MES sebesar 0.15 yang apabila dikalikan dengan 100\% akan menghasilkan nilai MES sebesar 15\%. Hasil perhitungan tersebut menunjukkan bahwa nilai MES lebih dari 1\% yang berarti terdapat hambatan masuk ke dalam pasar JESIGO. Hambatan utama yang dihadapi adalah keterbatasan modal. Menurut Manohar (2019), modal memiliki peran penting dalam sistem pemasaran jeruk. Banyak permasalahan pemasaran muncul karena dipicu oleh kekurangan modal (Gisti et al., 2018; Sharma \& Upadhayaya, 2020; Tijjani et al., 2019).

\section{Perilaku Pasar (Market Conduct)}

Analisis perilaku pasar akan menggambarkan perilaku setiap lembaga pemasaran dalam menghadapi struktur pasar yang ada. Adapun elemen yang terdapat dalam perilaku pasar meliputi lembaga dan praktek fungsi pemasaran serta sistem penentuan harga dan sistem pembayaran.

a. Lembaga dan Praktek Fungsi Pemasaran

Lembaga pemasaran menunjukkan badan usaha atau individu yang melakukan kegiatan atau fungsi pemasaran sehingga produk atau jasa akan berpindah dari produsen ke konsumen. Adapun lembaga pemasaran yang terlibat dalam pemasaran JESIGO di Kenagarian Koto Tinggi meliputi, petani, pedagang pengepul dan pedagang pengecer. Masing-masing lembaga pemasaran yang terlibat melakukan fungsi-fungsi pemasaran. Petani melakukan fungsi pertukaran berupa aktivitas penjualan, sementara pedagang pengepul dan pedagang pengecer melakukan fungsi pertukaran, fungsi fisik dan fungsi fasilitas. Fungsi fisik yang dilakukan berupa pengemasan produk, dan fungsi fasilitas yang dilakukan berupa standarisasi produk seperti grading.

Namun, semua fungsi-fungsi pemasaran masih dilakukan dengan sederhana. Keterbatasan modal dan keterampilan pelaku pemasaran menyebabkan fungsi pemasaran belum berjalan maksimal. Hal ini sejalan dengan pendapat (Deshmukh et al., 2021; Sharma \& Upadhayaya, 2020; Tijjani et al., 2019) menyatakan bahwa kendala dalam sistem pemasaran jeruk antara lain adalah grading, transportasi, penjualan hasil, pengemasan dan penyimpanan. Oleh karena itu, perlu kerjasama dengan berbagai pihak terutama pemerintah daerah untuk memberikan pelatihan 
maupun sarana dan prasarana lainnya agak praktek fungsi pemasaran dapat dilaksanakan lebih maksimal.

b. Saluran Pemasaran

Analisis saluran pemasaran dilakukan untuk melihat perilaku setiap lembaga pemasaran dalam menentukan saluran yang digunakan. Saluran pemasaran JESIGO yang terbentuk dari 20 petani responden adalah sebanyak 4 saluran. Seluruh petani responden menjual jeruk dalam bentuk buah utuh tanpa adanya proses pengolahan. Hal ini menggambarkan bahwa petani jeruk di Kengarian Koto Tinggi tidak melakukan perubahan nilai tambah terhadap jeruk yang mereka pasarkan. Rata-rata total produksi jeruk yang dihasilkan petani responden adalah 32 ton/ha per musim.
Gambar 1 menunjukkan bahwa sebagian besar petani memasarkan produknya ke pedagang pengepul $(86,86 \%)$, yang paling sedikit yaitu pemasaran ke konsumen langsung $(5,9 \%)$. Mayoritas petani $(86,86 \%)$ menjual hasil panen mereka kepada pengepul disebabkan karena kemudahan akses pendistribusian dan jaminan pasar yang menjanjikan. Menurut (Muzuna, 2019) petani memilih menjual kepada agen/ pengepul disebabkan karena mereka tidak memiliki pilihan lain, selain itu jumlah produksi yang terbatas mengakibatkan pilihan petani menjual kepada pengepul lebih efisien dibandingkan jika petani menjual langsung kepada konsumen.

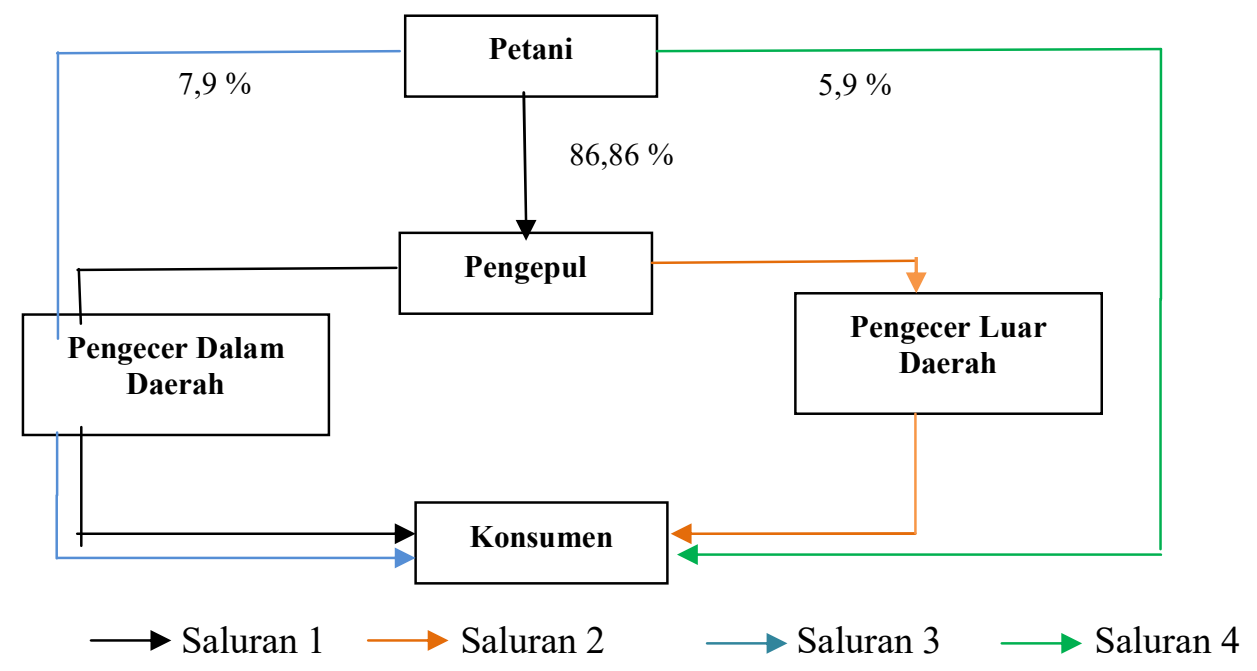

Gambar 1. Saluran Pemasaran Jeruk Siam 
c. Mekanisme Penentuan Harga

Secara teknis, penentuan harga JESIGO berdasarkan pada kualitas jeruk yang dipasarkan. Kualitas jeruk meliputi bentuk dan ukuran jeruk. Ditingkat pedagang pengepul hubungan kerjasama antar pengepul baik yang ada di daerah maupun diluar daerah memudahkan para pengepul mendapatkan informasi harga jeruk. Informasi ini dijadikan acuan bagi pedagang pengepul dalam proses penentuan harga beli jeruk bagi petani. Selain itu pengepul juga mendapatkan informasi harga dari pedagang besar provinsi dan juga dari harga pasar jeruk nasional.

Berdasarkan pertimbangan terhadap kondisi yang ada maka pedagang pengepul akan menentukan harga yang tepat untuk membeli jeruk petani. Posisi petani terhadap pedagang pengepul hanyalah sebagai penerima harga (price taker). Keterbatasan petani dalam memperoleh informasi harga dan keterikatan petani dengan pedagang pengepul, menyebabkan posisi tawar (bergaining position) petani menjadi lemah dalam proses penentuan harga. (Fahrunisa, 2020) menyatakan bahwa upaya yang dapat dilakukan petani untuk meningkatkan posisi tawarnya adalah dengan memperluas pangsa pasar.
Sehingga kemampuan petani dalam penentuan harga akan lebih kuat. Disisi lain pedagang pengecer yang merupakan perpanjangan tangan pedagang pengepul memperoleh informasi harga dari pedagang pengepul, sesama pengecer di pasar, dan juga dari tingkat permintaan jeruk di pasaran.

d. Sistem Pembayaran

Sistem pembayaran dalam pemasaran JESIGO di Kenagarian Koto Tinggi oleh masing-masing lembaga pemasaran sangat beragam, sesuai dengan situasi dan kondisi pada masingmasing lembaga pemasaran. Modal yang dimiliki oleh masing-masing lembaga pemasaran menjadi salah satu faktor yang mempengaruhi sistem pembayaran pada pemasaran JESIGO. Sistem pembayaran yang dilakukan dalam pemasaran JESIGO terdiri atas sistem pembayaran tunai dan sebagian/kemudian.

Pedagang pengepul biasanya memakai sistem pembayaran sebagian atau kemudian, karena pedagang pengepul membeli jeruk dalam volume yang banyak. Sistem pembayaran secara tunai biasanya dilakukan oleh pedagang pengecer, karena pedagang pengecer membeli dalam jumlah yang tidak terlalu banyak. Pedagang pengecer mampu membayar secara tunai karena perputaran 
modal yang terjadi di pedagang pengecer berlangsung secara cepat, hal ini disebabkan karena pengecer langsung turun ke pasar-pasar agar dapat menjangkau konsumen.

\section{Analisis Kinerja Pasar (Market}

\section{Peformance)}

Kinerja pasar (market performance) akan mencerminkan interaksi yang terjadi antara struktur pasar dan perilaku pasar (Panagiotou, 2006). Analisis yang digunakan untuk mengukur kinerja pasar adalah margin pemasaran dan farmer's share.

\section{Margin Pemasaran}

Analisis margin pemasaran JESIGO dilakukan pada lembaga pemasaran pedagang pengepul dan pedagang pengecer. Analisis margin ini bertujuan untuk melihat perbedaan harga di berbagai tingkat lembaga pemasaran.
Hasil analisis menunjukkan bahwa margin pemasaran, biaya pemasaran dan total keuntungan terbesar terdapat pada saluran 2 (petani-pengepul-pengecer luar daerah) yaitu secara berturut-turut sebesar Rp. 10.054/Kg atau 52,91 persen, Rp. 1.728 (9,09\%) dan Rp. 9.382 $(49,38 \%)$. Hal ini dapat disimpulkan bahwa meskipun margin pemasaran pada saluran 2 tinggi namun keuntungan yang diperoleh juga tinggi, karena jeruk dipasarkan di daerah-daerah dengan tingkat daya beli konsumen lebih tinggi. Hal ini sejalan dengan hasil penelitian (Badriadi et al., 2020; Chaerani, 2021; Kausadikar \& Nagargoje, 2019; Nilayani et al., 2021) yang menunjukkan bahwa variabel harga di tingkat konsumen dan jumlah lembaga pemasaran yang terlibat sangat berpengaruh terhadap marjin pemasaran komoditas pertanian.

Tabel 2. Analisis Margin Pemasaran dan Farmer's Share Jeruk Siam, Tahun 2020

\begin{tabular}{|c|c|c|c|c|c|c|c|}
\hline & \multirow{2}{*}{ Uraian (Rp/Kg) } & \multicolumn{6}{|c|}{ Saluran Pemasaran } \\
\hline No & & 1 & $\%$-Se & 2 & $\%$-Se & 3 & $\%$-Se \\
\hline \multirow[t]{2}{*}{1} & \multicolumn{7}{|l|}{ Petani } \\
\hline & a. Harga Jual & 8.946 & 50,52 & 8.946 & 47,09 & 10.250 & 57,99 \\
\hline \multirow[t]{11}{*}{2} & Pedagang Besar & & - & & - & & \\
\hline & a. Harga Beli & 8.946 & 50,52 & 8.946 & 47,09 & - & - \\
\hline & Biaya Pemasaran & & & & & - & - \\
\hline & Transportasi & 240 & 1,36 & 300 & 2,27 & - & - \\
\hline & Bongkar Muat & 125 & 1,03 & 150 & 1,14 & - & - \\
\hline & Sortasi \& Grading & 166 & 1,36 & 166 & 1,26 & - & - \\
\hline & Pengemasan & 260 & 1,47 & 260 & 1,97 & - & - \\
\hline & Penyusutan & 180 & 1,48 & 180 & 1,36 & - & - \\
\hline & Harga Jual & 12.182 & 68,78 & 13.200 & 69,47 & - & - \\
\hline & Keuntungan & 3.235 & - & 4.254 & - & - & - \\
\hline & $\begin{array}{l}\text { Margin Pedagang } \\
\text { e. Besar }\end{array}$ & 3.235 & - & 4.254 & - & - & - \\
\hline
\end{tabular}




\begin{tabular}{|c|c|c|c|c|c|c|c|}
\hline \multirow{2}{*}{ No } & \multirow{2}{*}{ Uraian (Rp/Kg) } & \multicolumn{6}{|c|}{ Saluran Pemasaran } \\
\hline & & 1 & $\%-\mathrm{Se}$ & 2 & $\%-\mathrm{Se}$ & 3 & $\%$-Se \\
\hline \multirow[t]{15}{*}{3} & Pengecer & & & & & & \\
\hline & a. Harga Beli & 12.182 & 68,78 & 13.200 & 69,47 & 10.250 & 57,99 \\
\hline & Biaya Pemasaran & & & & & & \\
\hline & Transportasi & 160 & 0,90 & 160 & 0,84 & 240 & 1,36 \\
\hline & Bongkar Muat & 125 & 0,71 & 150 & 0,79 & 125 & 0,71 \\
\hline & Sortasi \& Grading & 166 & 0,94 & 117 & 0,61 & 166 & 0,94 \\
\hline & Pengemasan & 45 & 0,25 & 45 & 0,24 & 260 & 1,47 \\
\hline & Penyusutan & 90 & 0,51 & 100 & 0,53 & 180 & 1,02 \\
\hline & Retribusi & 100 & 0,56 & 100 & 0,53 & 100 & 0,57 \\
\hline & Harga Jual & 17.710 & 100,00 & 19.000 & 100,00 & 17.676 & 100,00 \\
\hline & Keuntungan & 4.842 & & 5.128 & & 6.355 & \\
\hline & Margin Pengecer & 5.528 & & 5.800 & & 7.426 & \\
\hline & Total Biaya Pemasaran & 1.657 & 9,36 & 1.728 & 9,09 & 1.071 & 6,06 \\
\hline & Total Keuntungan & 8.078 & 45,61 & 9.382 & 49,38 & 6.355 & 35,95 \\
\hline & Total Margin & 8.764 & 49,48 & 10.054 & 52,91 & 7.426 & 42,01 \\
\hline
\end{tabular}

\section{Farmer's Share}

Farmer's share merupakan rasio antara harga di tingkat petani terhadap harga di tingkat pedagang. Besarnya farmer's share dipengaruhi oleh tingkat pemrosesan, biaya transportasi, keawetan produk dan jumlah produk (Kohls \& Uhl, 2002).

Berdasarkan hasil analisis farmer's share di Kenagarian Koto Tinggi dapat disimpulkan bahwa share harga yang diterima petani tergolong tinggi. Hal ini dikarenakan share yang diterima petani lebih dari 40 persen. Hal ini sejalan dengan pendapat Kohls dan Uhl (2002) yang menyatakan bahwa dalam aktivitas pemasaran komoditas pertanian share harga yang diterima petani dapat mencapai 40 persen atau lebih dari harga yang dibayarkan oleh konsumen.

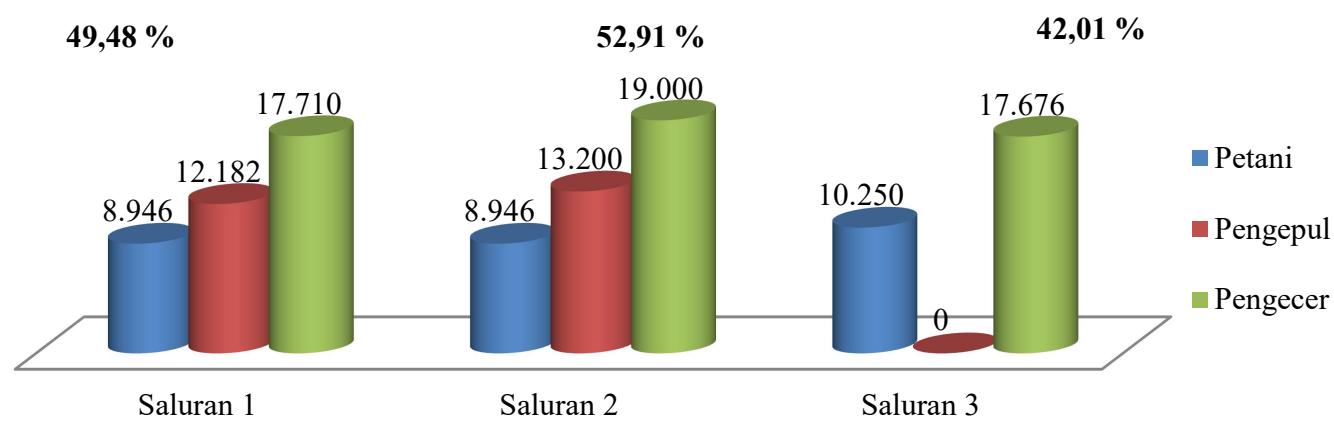

Gambar 3. Farmer's share pada Setiap Saluran Pemasaran Jeruk Siam

Hasil penelitian (Hasudungan et al., 2020) dan (Nilayani et al., 2021) juga menunjukkan bahwa share harga yang diterima petani jeruk siam pada semua saluran pemasaran relatif tinggi . Farmer's share yang tinggi 
menggambarkan bahwa harga jual jeruk siam masih relatif terjangkau bagi konsumen dan harga yang dibayarkan konsumen dapat dinikmati oleh petani.

\section{KESIMPULAN DAN SARAN}

\section{Kesimpulan}

Analisis struktur pasar jeruk siam Gunuang Omeh cenderung bersifat oligopsoni. Hambatan yang terjadi berupa keterbatasan modal. Kondisi perilaku pasar jeruk siam Gunuang Omeh menunjukkan terdapat beberapa lembaga yang terlibat dalam pemasaran JESIGO yaitu, petani, pedagang pengepul, pedagang pengecer dalam daerah, serta pedagang pengecer luar daerah. Kendala dalam fungsi pemasaran yaitu grading, transportasi dan penyimpanan. Struktur dan perilaku pasar yang terjadi mempengaruhi kinerja pasar. Analisis kinerja pasar menunjukkan bahwa, share harga jeruk siam Gunuang Omeh yang diterima petani sudah tergolong tinggi $(>40 \%)$.

\section{Saran}

Penelitian terkait komoditas jeruk siam Gunuang Omeh belum banyak dikaji. Oleh karenanya, perlu penelitian lanjutan terkait integrasi antar subsistem agribisnis jeruk siam gunuang omeh di
Kabupaten Lima Puluh Kota sehingga peran pemasaran dapat lebih dioptimalkan. Diharapkan keterlibatan pemerintah daerah dalam membantu memberikan pelatihan agar dapat meningkatkan nilai tambah jeruk siam Gunuang Omeh.

\section{DAFTAR PUSTAKA}

Badan Pusat Statistik. (2018a). Produksi Buah-Buahan Nasional. Badan Pusat Statistik.

Badan Pusat Statistik. (2018b). Sumatera Barat Dalam Angka 2017.

Badriadi, B., Fausayana, I., \& Nalefo, L. (2020). Analisis struktur, perilaku dan kinerja pasar rumput laut di Kabupaten Konawe Selatan. In Jurnal Sosio Agribisnis.

Chaerani, D. S. (2021). Analisis Marjin Pemasaran Jeruk Siam (Citrus nobilis Lour) di Kecamatan Pasaman Kabupaten Pasaman Barat. Jurnal Embrio, 13(1), 21-32. https://mail.ojs.unitaspdg.ac.id/index.php/embrio/article/ view/679

Cramer. (2009). Agriculture Economics and Agribusiness. John Wileey and Son.

Deshmukh, A., Agrawal, S., \& Jallaraph, V. (2021). Constraints Faced by Orange Growers about Production and Marketing Orange. International Journal of Agriculture, Environment and Biotechnology, 14(1), 11-16. https://search.proquest.com/openvie w/450de6980489c012c2cf8685684 b4302/1?pqorigsite $=$ gscholar $\&$ cbl $=2032162$

Fahrunisa, F. (2020). Analisis Pemasaran Jeruk Siam (Studi Kasus di Desa PIR ADB Dusun Bamban 
Kecamatan Besitang Kabupaten Langkat). repository.umsu.ac.id. http://repository.umsu.ac.id/handle/ $123456789 / 14407$

Gisti, S. E., Tarumun, S., \& Yusri, J. (2018). Analisis Pemasaran Jeruk Siam Gunung Omeh (Citrus nobilis lourvar) di Nagari Koto Tinggi Kecamatan Gunung Omeg Kabupaten Lima Puluh kota. Indonesian Journal of Agricultural Economics (IJAE), 9(1), 72-80. https://ijae.ejournal.unri.ac.id/index .php/IJAE/article/view/7106

Hasudungan, A., Tety, E., \& Eliza, E. (2020). Analisis Pemasaran Jeruk Siam (Citrus nobilis lourvar) di Desa Kuok Kecamatan Kuok Kabupaten Kampar. Indonesian Journal of Agricultural Economics (IJAE), 11(1), 30-45. https://ijae.ejournal.unri.ac.id/index .php/IJAE/article/view/7755

Kausadikar, H. H., \& Nagargoje, S. R. (2019). A study on price spread and marketing efficiency of sweet orange in Nalgonda district of Telangana. International Journal of Farm

https://www.indianjournals.com/ijo r.aspx? target $=$ ijor:ijfs \&volume $=9 \&$ issue $=1$ \& article $=009$

Kohls, R. ., \& Uhl. (2002). Marketing Of Agricultural Products. MacMillan Publishing Company.

Muzuna. (2019). Analisis Pemasaran Jeruk Siam (Studi Kasus: Desa Lasembangi Kecamatan Lasalimu Kabupaten Buton). Media Agribisnis, 3(2), 93-105. http://www.jurnalumbuton.ac.id/index.php/Agribisnis /article/view/491
Nilayani, N. L., Arnawa, I. K., \& Sukanteri, N. P. (2021). Pemasaran Jeruk Siam Kintamani. AGRIMETA, 11(21), 33-38. http://ejournal.unmas.ac.id/index.php/agri meta/article/view/2204

Panagiotou, G. (2006). The Impact of Managerial Cognitions on The Structure, Conduct, and Peformnace (SCP) Paradigm: A Strategic Group Perspective. Management Decision.

Putri, M. A., Fariyanti, A., \& Kusnadi, N. (2013). Struktur dan Integrasi Pasar Kopi Arabika Gayo di Kabupaten Aceh Tengah dan Bener Meriah. Buletin RISTRI, 4(1), 47-54.

Sharma, S., \& Upadhayaya, S. (2020). Marketing of Mandarin Orange in Jajarkot District: a Value Chain Analysis. Malaysian E Commerce Journal, 4(1), 05-08. https://doi.org/10.26480/mecj.01.20 20.05.08

Tijjani, M. S., Wakawa, R. C., Goni, M., \& Bukar, A. U. (2019). Marketing of Orange Fruit in Maiduguri Metropolitan Area, Borno State, Nigeria. Journal of Biology, Agriculture and Healthcare, 9(22), 7-12. https://doi.org/10.7176/jbah/9-2202. 